\title{
ANÁLISE E MAPEAMENTO DO USO E OCUPAÇÃO DO SOLO DA BACIA DO ALTO DO DESCOBERTO, DF/GO, POR MEIO DE CLASSIFICAÇÃO AUTOMÁTICA BASEADA EM REGRAS E LÓGICA NEBULOSA ${ }^{1}$
}

\author{
Juliana Faria Nunes ${ }^{2}$ e Henrique Llacer Roig ${ }^{3}$
}

\begin{abstract}
RESUMO - A Bacia do Alto do Descoberto é importante fonte de água para o Distrito Federal. Essa bacia tem apresentado ao longo dos anos expansão agrícola e urbana em detrimento das áreas de vegetação natural. A ocupação inadequada, assim como a falta de planejamento do uso e ocupação do solo, pode levar a alterações do escoamento superficial e, consequentemente, do ciclo hidrológico, a feições erosivas, à contaminação dos mananciais superficiais e subterrâneos e ao desequilíbrio do ecossistema da região. Portanto, o monitoramento e a análise do uso e ocupação do solo são imprescindíveis na prevenção desses impactos e na manutenção dos mananciais. Dessa forma, este estudo tem como objetivo o mapeamento e a análise comparativa do uso e ocupação do solo da Bacia do Alto do Descoberto entre os anos 1994 e 2011. As classificações de uso e ocupação do solo foram elaboradas utilizando um classificador orientado ao objeto baseado em regras e lógica nebulosa, permitindo uma análise dos avanços do uso do solo e a perda da cobertura vegetal da bacia. O sistema de classificação utilizado foi considerado bem-sucedido, com índice de exatidão temática (Kappa) de 0,64. Apesar de ainda haver algumas confusões temáticas no processo de classificação, as análises comparativas entre as classes temáticas dos mapas dos referidos anos evidenciaram a forte expansão agrícola da região em aproximadamente $11 \%$ da área da bacia, bem como uma perda de vegetação natural.
\end{abstract}

Palavras-chave: Uso e ocupação do solo; Classificação orientada ao objeto; ENVI EX.

\section{LAND USE AND LAND OCCUPATION ANALYSIS AND MAPPING OF THE ALTO DESCOBERTO HYDROGRAPHIC BASIN, DF/GO, USING A FUZZY RULE-BASED AUTOMATIC CLASSIFICATION}

\begin{abstract}
The Alto Descoberto basin is an important water source for the Distrito Federal. During the past years, this basin has suffered an agriculture and urban expansion over the natural areas. The inadequate land use associated with a lack of planning the use and occupation of the land, can lead to alteration in the superficial water flow and hydrological cycle, to siltation, to pollution of the superficial and underground water bodies and also towards an unbalanced environment in the region. Because of that, the monitoring and analysis of land use and occupation are extremely needed in the prevention of these impacts and maintenance of the water bodies. Keeping that in mind, this study aimed to perform the mapping and comparative analysis of the land use and occupation of the soil of the Alto do Descoberto basin between 1994 and 2011. The classifications of use and occupation of the soil were elaborated using a classifier oriented to the fuzzy rulebased object, allowing the analysis of the advances of the soil use and loss of vegetal coverage of the basin. The classification system was considered successful, with thematic accuracy (Kappa index) of 0.64. Although there are still some thematic confusions during the classification process, the comparative analysis among theme classes of the maps of the referred years showed a strong agriculture expansion of the region in approximately $11 \%$ of the river basin area, as well as a loss of the natural vegetation.
\end{abstract}

KEYWORDS: Land use and occupation; Object-based classification; ENVI EX.

\footnotetext{
${ }^{1}$ Recebido em 24.02.2013 aceito para publicação em 19.11.2014.

${ }^{2}$ Universidade de Brasília, Programa de Pós-Graduação em Geociências Aplicada, Área de Concentração em Geoprocessamento, Brasília, Distrito Federal - Brasil. E-mail:<jules.nunes@gmail.com>.

${ }^{3}$ Instituto de Geociências, Universidade de Brasília, Brasília, Distrito Federal - Brasil. E-mail: <roig@unb.br>.
} 


\section{INTRODUÇÃO}

A Bacia do Alto do Descoberto é responsável por cerca de $66 \%$ do abastecimento de água do Distrito Federal (SPERA et al., 2003). A região está contida no bioma Cerrado, contemplando várias de suas fitofisionomias e podendo servir de rota migratória para a fauna proveniente do Parque Nacional de Brasília (GREEN ENG. AMBIENTAL, 1998).

As principais atividades econômicas desenvolvidas na região são representadas pela produção de hortaliças, de frutas, de carne bovina, de aves e de ovos, sendo importante polo agrícola (SPERA et al., 2003). O crescimento dessas atividades ao longo dos anos foi realizado de forma insustentável, com ocupação irregular do solo, desmatamento, invasão das margens de rios e nascentes e disposição incorreta do lixo (BRASIL, 2009).

O uso e ocupação inadequados do solo podem comprometer a integridade das bacias hidrográficas (ARCOVA; CICCO, 1999; DONATIO et al., 2005). O desmatamento pode levar ao surgimento de feições erosivas e assoreamento dos rios e reservatórios. A impermeabilização do solo através da expansão urbana pode afetar a percolação das águas pluviais e o regime hídrico (CARVALHO et al., 2000), e a expansão agrícola extensiva pode causar a contaminação das águas por fertilizantes e agrotóxicos através do processo natural de lixiviação (MACEDO, 2004). Portanto, devido à importância dos recursos naturais presentes na Bacia e ao histórico de ocupação irregular, torna-se imprescindível que haja planejamento integrado do uso e ocupação do solo.

A utilização do sensoriamento remoto na obtenção de dados relacionados ao uso e ocupação do solo para monitoramento e análises dos recursos naturais tem sido bastante difundida. Os sensores atualmente disponíveis possuem diferentes resoluções espaciais, espectrais, radiométricas e temporais, possibilitando maiores níveis de informação a serem extraídos dos dados (SANO et al., 2009).

Entre as informações relevantes na classificação do uso e ocupação do solo, encontram-se a forma, a textura, a resposta espectral e o contexto espacial dos objetos (LOCK; KIRCHNER, 1997). Atualmente, a tendência dos classificadores automáticos é a incorporação dessas variáveis a partir da utilização de técnicas como OBIA (do inglês object-based image analysis), que utilizam a segmentação de objetos, o conceito de lógica nebulosa e o conhecimento prévio do usuário (HAY; CASTILLA, 2006).

Essas técnicas estão disponíveis em alguns aplicativos, como o Interimage (INTERIMAGE, 2010), o E-Cognition (DEFINIENS;-COGNITION, 2012) e o ENVI EX (ENVI, 2008). O software ENVI EX apresenta um módulo denominado ENVI Feature extraction (FX). Esse módulo é um classificador orientado ao objeto e baseado em conhecimento, utilizando regras e lógica nebulosa (fuzzy) para a extração das feições de imagens de satélite (ENVI, 2008).

O workflow ENVI FX apresenta cinco etapas: segmentação, fusão (merge), refinamento, computação de atributos e extração das feições por regras ou por classificação supervisionada. A extração por regras é realizada por meio da construção de um conjunto de regras para as feições visualizadas. Cada regra pode apresentar $n$ atributos a serem definidos pelo usuário, sendo estes: atributos espaciais, atributos relacionados à textura e atributos espectrais, assim como color space (alocação do modelo RGB) e razão de bandas, que pode ser utilizado para geração de índices como o NDVI (do inglês, Normalized Difference Vegetation Index) (ENVI, 2008).

Cada segmento da imagem apresenta diferentes valores de pertinência em relação aos atributos selecionados no software, de acordo com o conceito de lógica nebulosa que, ao contrário da lógica booleana, é utilizada para expressar conceitos inexatos. Valores de 0 a 1 são estabelecidos para os objetos, variando de um conjunto $A$ (pertencentes) para um conjunto $B$ (não pertencentes) e utilizando determinada função de pertinência (ZADEH, 1975). Dessa forma, é possível obter refinamento na classificação de cada objeto, visto que diferentes objetos podem possuir diferentes valores de pertinência para o mesmo atributo sem ser necessariamente da mesma classe temática.

A partir da utilização desses conceitos, este trabalho teve como objetivo o mapeamento do uso e ocupação do solo por meio da classificação temática de imagens do sensor Thematic Mapper (TM) a bordo do satélite Landsat 5 e pelo software ENVI EX, bem como analisar as mudanças de uso e ocupação do solo na região a partir das classificações obtidas nos anos 1994 e 2011.

Revista Árvore, Viçosa-MG, v.39, n.1, p.25-36, 2015

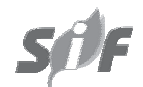




\section{MATERIAL E MÉTODOS}

O mapeamento do uso e ocupação do solo para o tempo inicial (T1) de 1994 e para o tempo final (T2) de 2011 foi realizado utilizando imagens do sensor Thematic Mapper (TM), de 25/07/1994 e 08/07/2011, e demais dados, por meio do módulo ENVI FX, tendo como base a chave de classificação estabelecida. Após as classificações e análise da exatidão temática, investigações das modificações no uso e ocupação do solo entre os tempos T1 e T2 para a área de estudo foram realizadas. Dessa forma, foram seguidas as seguintes etapas, detalhadas nos tópicos a seguir:

1. Construção da chave de classificação.

2. Obtenção dos dados de entrada:

a. Obtenção das imagens de satélite;

b. Obtenção de dados auxiliares para classificação; e

c. Obtenção de máscaras para classificação.

3. Classificação das imagens no ENVI FX.

4. Análise da classificação temática.

5. Análise do uso e ocupação do solo.

A área de estudo refere-se à parte a montante da barragem do rio Descoberto, denominada Bacia do Alto do Descoberto, pertencente à Bacia do Rio Paraná, com aproximadamente $437 \mathrm{~km}^{2}$. Localiza-se entre o Estado de Goiás e o Distrito Federal, no quadrante de $\mathrm{S} 15^{\circ} 35^{\prime} 00^{\prime \prime}$ a S $15^{\circ} 48^{\prime} 00^{\prime \prime}$ de latitude sul e de W48 $08^{\prime} 00^{\prime \prime}$ a $48^{\circ} 15^{\prime} 00^{\prime \prime}$ de longitude Oeste (Figura 1).

\subsection{Chave de classificação}

A construção da chave de classificação foi realizada a partir da análise das feições presentes na área de estudo. Tendo em vista que a imagem utilizada para interpretação é proveniente do sensor Thematic Mapper (TM) a bordo do satélite Landsat 5, a chave obtida (Figura 2) leva em consideração as resoluções espaciais e espectrais da imagem.

A divisão da chave de uso e ocupação ocorreu inicialmente entre vegetação e não vegetação, e a parte de não vegetação compreende as classes temáticas finais: corpos d' água, construções e edificações e solo exposto que, devido às características da imagem, seguem as seguintes definições:

- Corpos d' água: englobam tanto corpos d' água naturais como lagos e lagoas quanto corpos d'água artificiais, como é o caso do Lago do Descoberto, originado a partir do barramento do rio do Descoberto, iniciado em 1973.

- Construções e edificações são constituídas por vilas, cidades, estradas, complexo industrial e outras obras antrópicas.

- A classe solo exposto contém áreas que no momento de captação da imagem não apresentavam vegetação, podendo ser uma região de pousio tanto da agricultura quanto de uma área degradada.

A vegetação foi subdivida de acordo com as características do estrato arbóreo da cobertura vegetal: formações florestais, formações savânicas e formações campestres, conforme a classificação de Ribeiro e Walter (1998). No entanto, tal classificação para vegetação natural foi estendida às áreas com vegetação alterada, como vegetação agrícola e reflorestamento.

As formações florestais são áreas com predomínio do estrato arbóreo e com formação de dossel contínuo ou descontínuo; essa classe foi dividida nas classes finais:

- Mata de galeria e ciliar: caracterizadas por acompanharem os cursos d'água, sendo a mata de galeria caracterizada por ter o dossel fechado. Apesar dessa distinção, essas duas classes permaneceram juntas devido à impossibilidade de separação pela resolução espacial da imagem.

- Reflorestamento: áreas destinadas à silvicultura, que foram alocadas dentro de formações florestais devido ao seu estrato arbóreo pronunciado. No entanto, devido às limitações da imagem utilizada, não foi possível separar os tipos de reflorestamento a partir da espécie manejada.

As formações savânicas não apresentam a formação de um dossel e possuem um estrato graminoso com arbustos e árvores (RIBEIRO; WALTER, 1998). Essa classe engloba as classes Cerrado denso, Cerrado ralo, Cerrado rupestre e Cerrado típico, que foram alocadas na mesma classe denominada Savana.

As formações campestres são caracterizadas por possuírem um estrato herbáceo-arbustivo. Entre as vegetações naturais dessa classe, encontram-se o campo limpo, o campo sujo e o campo rupestre (RIBEIRO; WALTER, 1998). Essa classe engloba as seguintes classes finais:

Revista Árvore, Viçosa-MG, v.39, n.1, p.25-36, 2015 


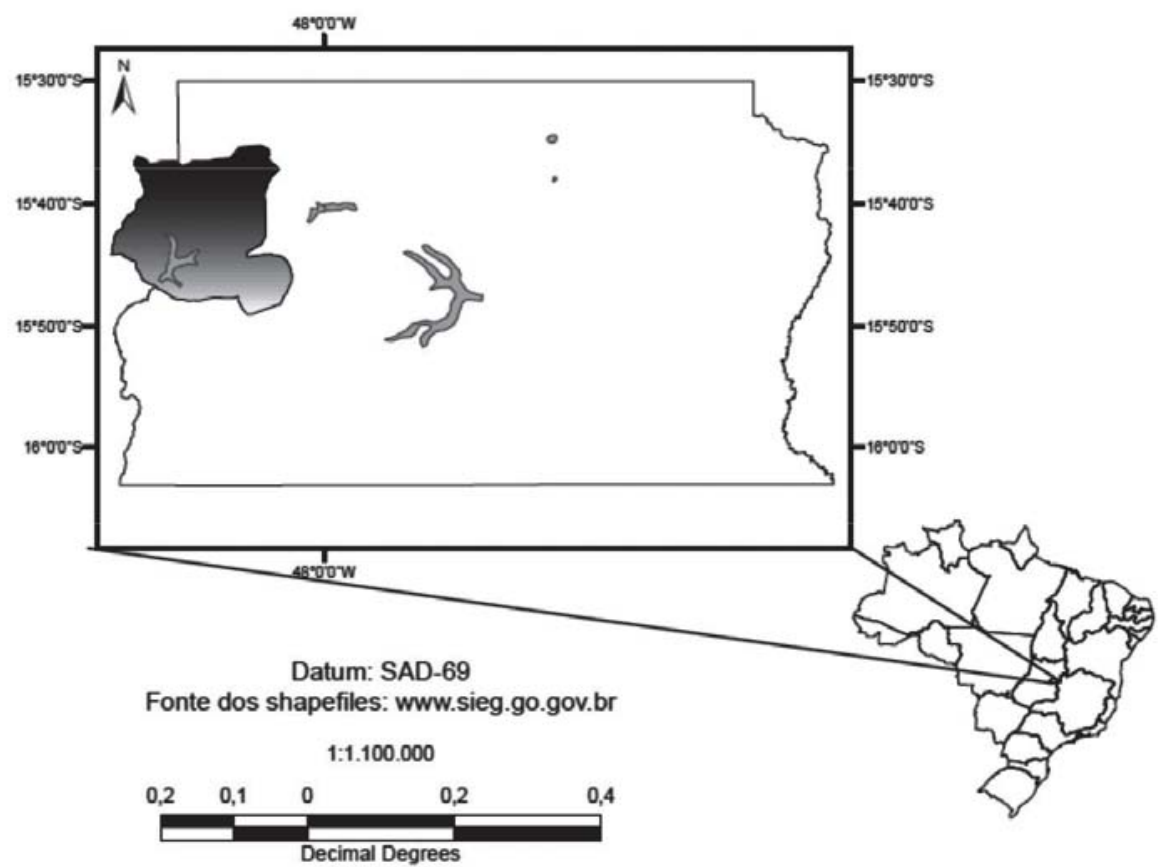

Figura 1 - Mapa de localização da área de estudo.

Figure 1 -Location map of the study area.

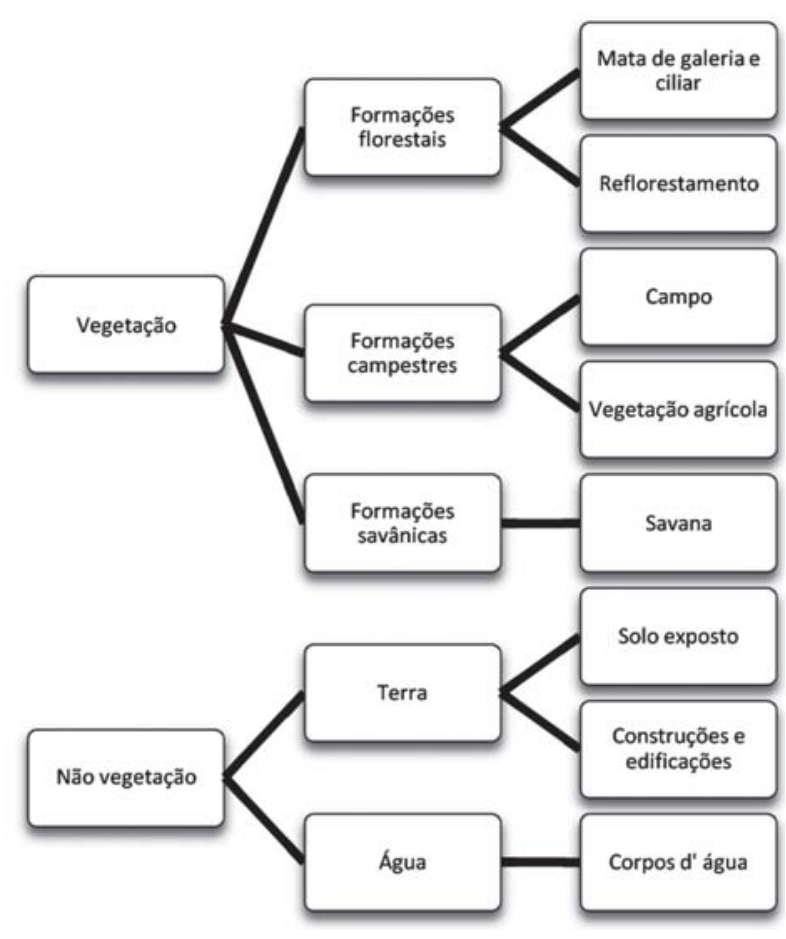

Figura 2 - Chave de classificação.

Figure 2 - Classification key.
- Campo: agrupa todas as fitofisionomias campestres naturais, assim como as áreas destinadas ao uso pastoril.

- Vegetação agrícola: agrupa loteamentos contendo agricultura irrigada, sequeira e pivô central. Foi alocada juntamente com a classe Campo dentro da classe formações campestres. Isso ocorreu devido às características arbustivas e gramíneas das culturas desenvolvidas na região.

\subsection{Obtenção dos dados e classificação das imagens}

As imagens utilizadas para classificação foram obtidas do Serviço Geológico dos Estados Unidos (USGS), que proporciona acurácia radiométrica e geométrica. As imagens datam de 25 de julho de 1994 e de 8 de julho de 2011, órbita/ponto 221/071, ambas no Sistema de coordenadas WGS84, sendo escolhidas devido à baixa incidência de nuvens e por serem do mesmo período do ano, a fim de minimizar interferências climáticas na interpretação das imagens. Essas imagens foram transformadas para o sistema de coordenadas adotado no Distrito Federal, de acordo com o Decreto Distrital no 4.008, de 1977, denominado SICAD (Projeção: UTM e datum: Astro Chuá), utilizando os parâmetros

Revista Árvore, Viçosa-MG, v.39, n.1, p.25-36, 2015 
$\Delta \mathrm{x}=143,87, \Delta \mathrm{y}=-243,37 \mathrm{e} \Delta \mathrm{z}=33,52$ para, posteriormente, serem recortadas com o shapefile de delimitação da bacia.

O primeiro passo para a realização da classificação foi a construção de máscaras para separar áreas de vegetação de áreas de não vegetação, conforme a chave de classificação. O intuito dessa separação é a aplicação de parâmetros diferentes de segmentação e fusão (merge) do ENVI FX para essas duas regiões, que apresentam padrões distintos.

Essa separação foi realizada com base no NDVI (1), que tem como variáveis em sua equação a intensidade de energia eletromagnética aferida pelo sensor nas bandas do infravermelho próximo ( $\rho$ nir) e do vermelho (pred). Esse índice varia de- 1 a $1 \mathrm{e}$ constitui um bom separador de áreas com biomassa fotossinteticamente ativa, estando áreas com maior proporção de biomassa mais próximas de 1 e áreas com menor proporção de biomassa, mais próximas de - 1 (ROUSE et al., 1973).

$$
\text { NDVI }=(\rho n i r-\rho r e d) /(\rho n i r+\rho r e d)
$$

O algoritmo TA NDVI segmenter do software Interimage foi utilizado para realizar essa separação inicial entre vegetação e não vegetação. Esse algoritmo permite a entrada de parâmetros como o limiar de valor de NDVI, que determinará a segmentação da imagem em dois grandes segmentos, sendo o limiar utilizado de 0,12 (CASTEJON; DE PINHO, 2011). Os resultados obtidos no Interimage foram exportados em shapefiles e utilizados para gerar duas máscaras para cada imagem: máscara vegetação e máscara não vegetação (invertida), sendo ambas complementares.

A hidrografia da região foi obtida no formato shapefile, sistema de coordenadas SICAD, e transformada em raster para ser utilizada como dado de entrada auxiliar para facilitar a extração da feição matas de galeria e ciliar.

A partir das máscaras construídas, duas classificações foram feitas para cada imagem: uma para cada máscara. Os dados de entrada utilizados no workflow do ENVI FX foram:

- Imagem Landsat 1994 ou 2011 (bandas 1, 2, 3, 4, 5 e 7).

- Máscara vegetação juntamente com a hidrografia em raster.

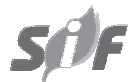

- Máscara não vegetação somente.

Os parâmetros utilizados dentro do workflow para segmentação e merge foram definidos empiricamente para os valores 40.0 e 90.0 , respectivamente, nas duas imagens dentro da máscara vegetação. Enquanto os parâmetros utilizados na máscara não vegetação tiveram pequena variação entre as imagens, sendo 34.0 e 95.0 para o ano 1994 e 34.0 e 80.0 para o ano 2011. Em nenhuma das classificações foi aplicada a ferramenta de refinamento disponibilizada.

As imagens foram visualizadas no modelo 543 RGB, bem como foram computados todos os atributos disponíveis, sendo customizada a razão de bandas para expressar o índice NDVI, alocando-se a banda 3 (banda do vermelho) e a banda 4 (banda do infravermelho próximo) nos parâmetros do software. Conjuntos de regras para cada classe estipulada foram criados, sendo dois conjuntos de regras por imagem: um conjunto para a máscara vegetação e outro para a máscara não vegetação.

\subsection{Análise da classificação temática}

A região da bacia de estudo foi percorrida, e 93 pontos de controle (Ground control points - GCPs) foram coletados, utilizando-se um GPS para avaliar a exatidão temática da classificação realizada para o ano 2011. Esses pontos foram transformados em shapefile para, posteriormente, serem convertidos em raster (30 m x $30 \mathrm{~m})$ no sistema de coordenadas SICAD. Após a transformação em raster dos GCPs coletados, foi feito um pós-processamento para verificar se a área do raster obtida a partir dos pontos de campo abrangia somente a feição observada em campo. A partir desse raster validado, foi realizada uma tabulação cruzada com a classificação temática para o ano 2011, por meio da ferramenta Combine do software Arcgis 10.

A matriz de confusão gerada (Tabela 1) entre os GCPs e a classificação realizada foi utilizada para realização do cálculo do índice Kappa (2), em que Po representa a proporção global de concordância observada e Pe, a proporção global de concordâncias esperadas pelo acaso. Esse índice varia de 0 a 1 , significando total concordância entre os dados quando se obtém o valor máximo (COHEN, 1960).

$$
\mathrm{K}=(\mathrm{Po}-\mathrm{Pe}) /(1-\mathrm{Pe})
$$

O desempenho do índice Kappa foi avaliado de acordo com a tabela de desempenho proposta por

Revista Árvore, Viçosa-MG, v.39, n.1, p.25-36, 2015 
Tabela 1 - Matriz de confusão.

Table 1 - Confusion matrix.

\begin{tabular}{|c|c|c|c|c|c|c|c|c|c|}
\hline GCP & $\begin{array}{l}\text { Corpos } \\
\text { d' água }\end{array}$ & Campo & $\begin{array}{l}\text { Vegetação } \\
\text { agrícola }\end{array}$ & Savana & $\begin{array}{c}\text { Mata de } \\
\text { galeria } \\
\text { e ciliar }\end{array}$ & $\begin{array}{l}\text { Refloresta- } \\
\text { mento }\end{array}$ & $\begin{array}{c}\text { Solo } \\
\text { exposto }\end{array}$ & $\begin{array}{l}\text { Construções e } \\
\text { edificações }\end{array}$ & Total \\
\hline \multicolumn{10}{|l|}{2011} \\
\hline Corpos d' água & 1 & & & & & & & & 1 \\
\hline Campo & & 17 & 4 & 11 & & & & & 32 \\
\hline Vegetação agrícola & & 3 & 16 & 1 & & 1 & 1 & & 22 \\
\hline Savana & & 2 & & 9 & & 1 & & & 12 \\
\hline Mata de galeria e ciliar & & & 1 & & 9 & & & & 10 \\
\hline Reflorestamento & & & & & & 4 & & & 4 \\
\hline Solo exposto & & & 1 & & & & 4 & & 5 \\
\hline Construções e edificações & & & & & & & 1 & 6 & 7 \\
\hline Total & 1 & 22 & 22 & 21 & 9 & 6 & 6 & 6 & 93 \\
\hline
\end{tabular}

Fonseca (2000), em que índices entre 0,21 e 0,4 são considerados razoáveis e entre 0,41 e 0,6 , bons; e entre 0,61 e 0,8 , muito bons; e entre 0,81 e 1 , excelentes.

\subsection{Análises do uso e ocupação}

Os resultados da classificação foram utilizados como dado de entrada para as análises de uso e ocupação do solo. O software Arcgis 10 foi utilizado como ferramenta para obtenção dessa análise comparativa.

Os shapefiles obtidos foram concatenados em um geodatabase e utilizados para os cálculos da área, em hectare, e para o cálculo da porcentagem das classes finais empregadas nas classificações. Tais dados serviram de base para a observação da tendência da dinâmica de uso na bacia, por meio de um gráfico comparativo e de análises espaciais.

\section{RESULTADOS}

\subsection{Análise do mapeamento do uso e ocupação do solo}

A classificação automática das imagens orientada ao objeto resultou em dois mapas de uso e ocupação do solo da Bacia do Alto do Descoberto, para os anos 1994 e 2011 (Figuras 3 e 4, respectivamente).

Devido ao fato de o workflow ENVI FX possuir somente um nível de segmentação, foi necessária a criação de uma máscara para a primeira divisão da imagem entre vegetação e não vegetação. A utilização da máscara possibilita a utilização de parâmetros diferentes de segmentação, delimitando os objetos a serem identificados de acordo com as regras formuladas para as classes temáticas previstas na chave de classificação adotada. Apesar de essa metodologia ter suprido a primeira divisão dicotômica da chave de classificação, persistiram segmentos não representativos dos alvos devido à não individualização da segmentação de cada classe final.

Durante o processo de classificação, foi possível observar algumas confusões temáticas nas classificações geradas. Isso ocorreu principalmente devido à utilização de diferentes atributos disponibilizadas no software na tentativa de englobar todos os segmentos das respectivas classes temáticas. Outra questão é que muitos segmentos de determinados alvos não apresentavam altos valores de pertinência em relação aos atributos, possuindo valores medianos juntamente com segmentos de outras feições, dificultando sua extração.

As confusões temáticas foram bastante perceptíveis entre as classes solo exposto e construções e edificações, visto que os segmentos dessas classes apresentaram respostas espectrais e espaciais similares, como os atributos relacionados à forma. Uma das características das classes solo exposto e construções e edificações é o baixo valor de NDVI, que também pode ser atribuído a áreas de campo onde a vegetação está pouco densa $\mathrm{e}$, consequentemente, com menor proporção de biomassa fotossinteticamente ativa. Esse fator pode gerar confusões na classificação entre segmentos da classe campo que apresentem esse baixo valor de NDVI e as classes solo exposto e construções e edificações.

A área de estudo apresentava em sua porção central uma região de intensa atividade agrícola com culturas 


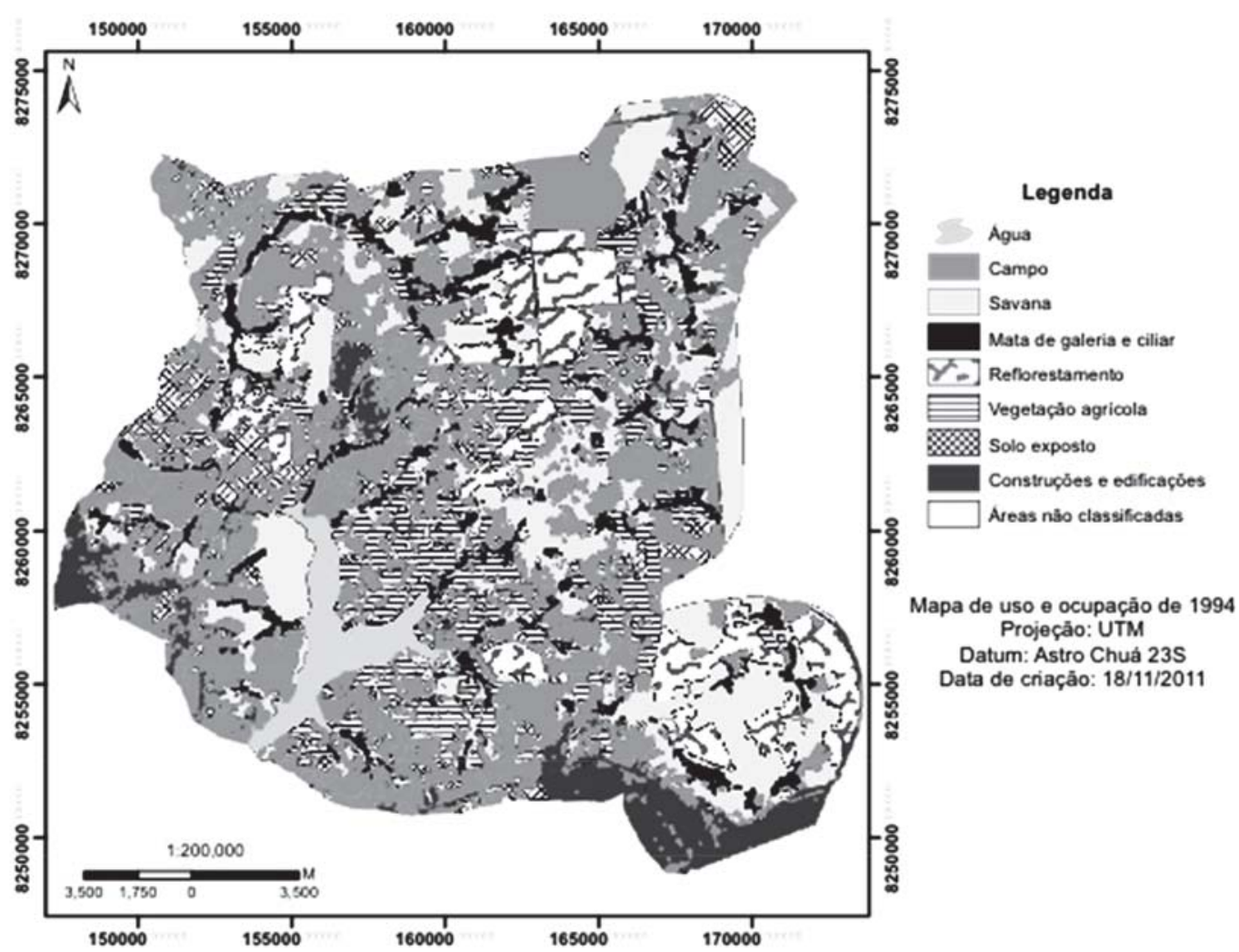

Figura 3 - Mapa de uso e ocupação do solo da Bacia do Descoberto do ano 1994.

Figure 3 - Land use and occupation map from 1994 of the Alto Descoberto basin.

bem desenvolvidas. Esses segmentos possuíam alto valor digital nos atributos relacionados à banda do infravermelho próximo, que é a parte do espectro intensamente refletida pela vegetação fotossinteticamente ativa, típica de estratos arbóreos. Dessa forma, alguns segmentos das classes reflorestamento e mata de galeria e ciliar que apresentavam valores similares aos segmentos anteriormente descritos foram confundidos com a classe vegetação agrícola.

Outra confusão temática recorrente foi entre as classes reflorestamento e savana. Essa confusão ocorreu entre os segmentos de reflorestamento que não apresentavam ainda textura característica formada pela copa das árvores, típico dessa cobertura vegetal, estando nos estágios iniciais do plantio. Dessa forma, os segmentos de savana com maior quantidade arbórea continham valores de pertinência similares em relação aos atributos utilizados nas regras de classificação da classe reflorestamento.
Apesar da existência dessas confusões temáticas observadas nas construções das regras e consequentemente nas classificações realizadas, acreditase que os mapas gerados, tanto de 1994 quanto de 2011 (Figuras 3 e 4, respectivamente), contenham um panorama da situação do uso e ocupação do solo da bacia, não interferindo significativamente nas análises realizadas a partir desses resultados.

Essa suposição foi comprovada ao realizar as análises de exatidão temática através do índice Kappa. Alguns dos conflitos entre as classes temáticas observadas nas classificações foram corroboradas pelas análises de campo, sendo também possível observar áreas passíveis de serem englobadas em outras classes temáticas devido à resolução espacial da imagem.

Os pontos coletados e a imagem de classificação do ano 2011 foram utilizados para gerar uma matriz de confusão para o cálculo do índice Kappa, sendo a maior confusão observada na matriz entre as classes

Revista Árvore, Viçosa-MG, v.39, n.1, p.25-36, 2015

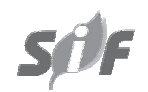




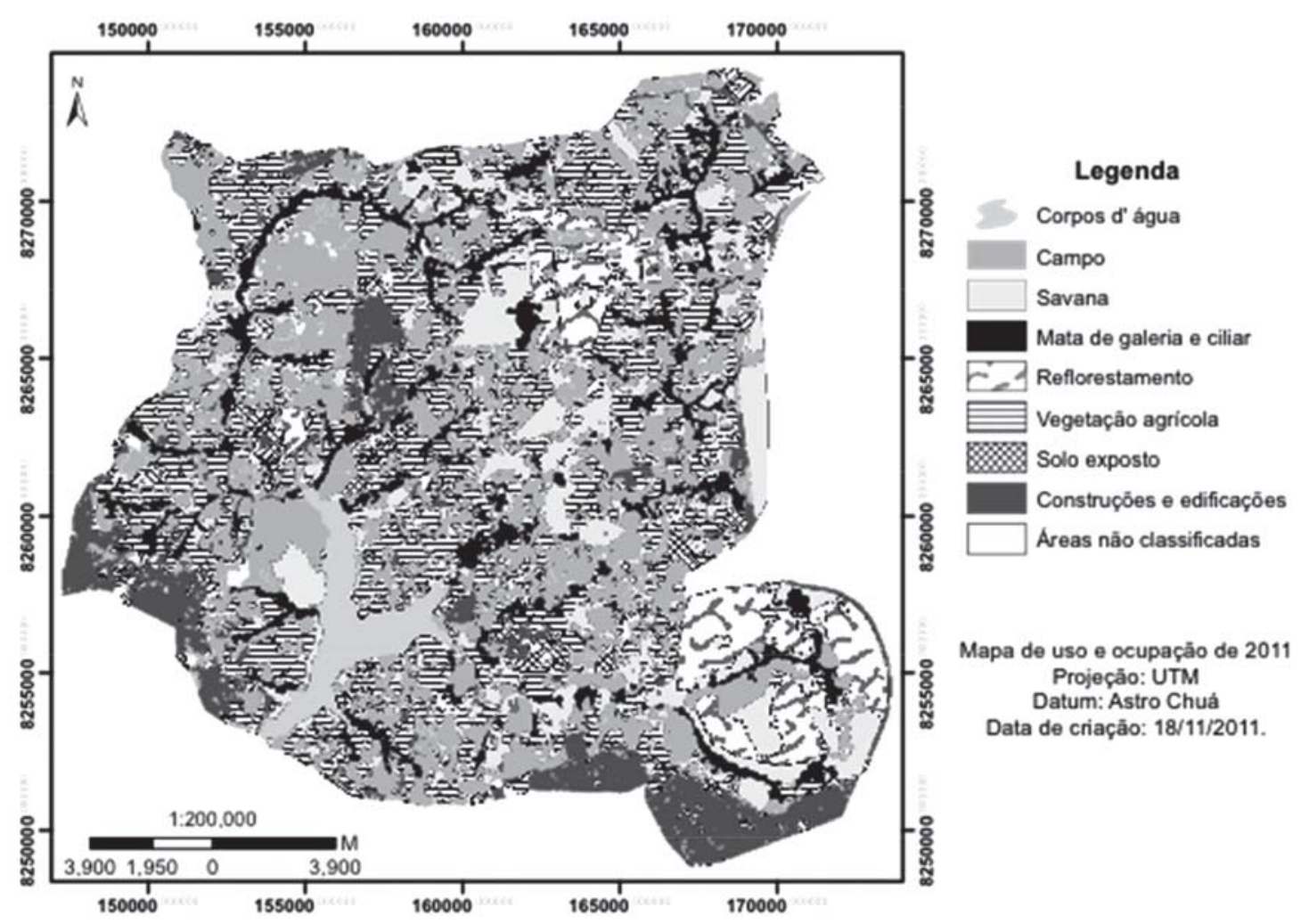

Figura 4 - Mapa de uso e ocupação do solo da Bacia do Descoberto do ano 2011. Figure 4 - Land use and occupation map from 2011 of the Alto Descoberto basin.

savana e campo. O índice Kappa obtido foi no valor de 0,64 (64\%), com Po=0,709677 e Pe =0,188114. Esse valor representa desempenho muito bom, de acordo com a tabela proposta por Fonseca (2000), evidenciando que, de forma geral, a classificação realizada apresenta um panorama da bacia e é representativa das classes temáticas analisadas.

\subsection{Análises do uso e ocupação do solo}

As análises de uso e ocupação do solo para a referida bacia foram feitas baseadas nos resultados de classificação obtidos anteriormente. Os shapefiles das classes temáticas resultantes da classificação foram utilizados para os cálculos da extensão territorial e para a análise comparativa entre as classes nos tempos T1 e T2.

Comparando a porcentagem de cada classe em relação à bacia, é possível ter um dado mais consistente para avaliar a dimensão de cada feição (Figura 5). Apesar da construção de inúmeras regras de cada classe temática na tentativa de englobar todos os segmentos das respectivas feições, alguns segmentos permaneceram não classificados devido às suas características díspares em relação aos outros segmentos da mesma feição.

Ao comparar as áreas (em porcentagem em relação à área da bacia) de cada classe entre os anos 1994 e 2011, constatou-se aumento significativo das áreas de vegetação agrícola (aproximadamente 11\%) em detrimento das áreas de campo e savana (aproximadamente 6\% cada). Esse aumento de 11\% em relação à área da bacia equivale a um aumento de quase o dobro da área destinada à agricultura. Outro ponto importante foram a diminuição das áreas ocupadas por reflorestamento (aproximadamente $2 \%$ ) e o aumento das áreas de construções e edificações (áreas urbanas), principalmente devido às expansões das cidades de Águas Lindas, Padre Bernardo e o Município de Alexandre Gusmão.

A diminuição na porcentagem da classe solo exposto evidencia o fato de as áreas de preparação agrícola 


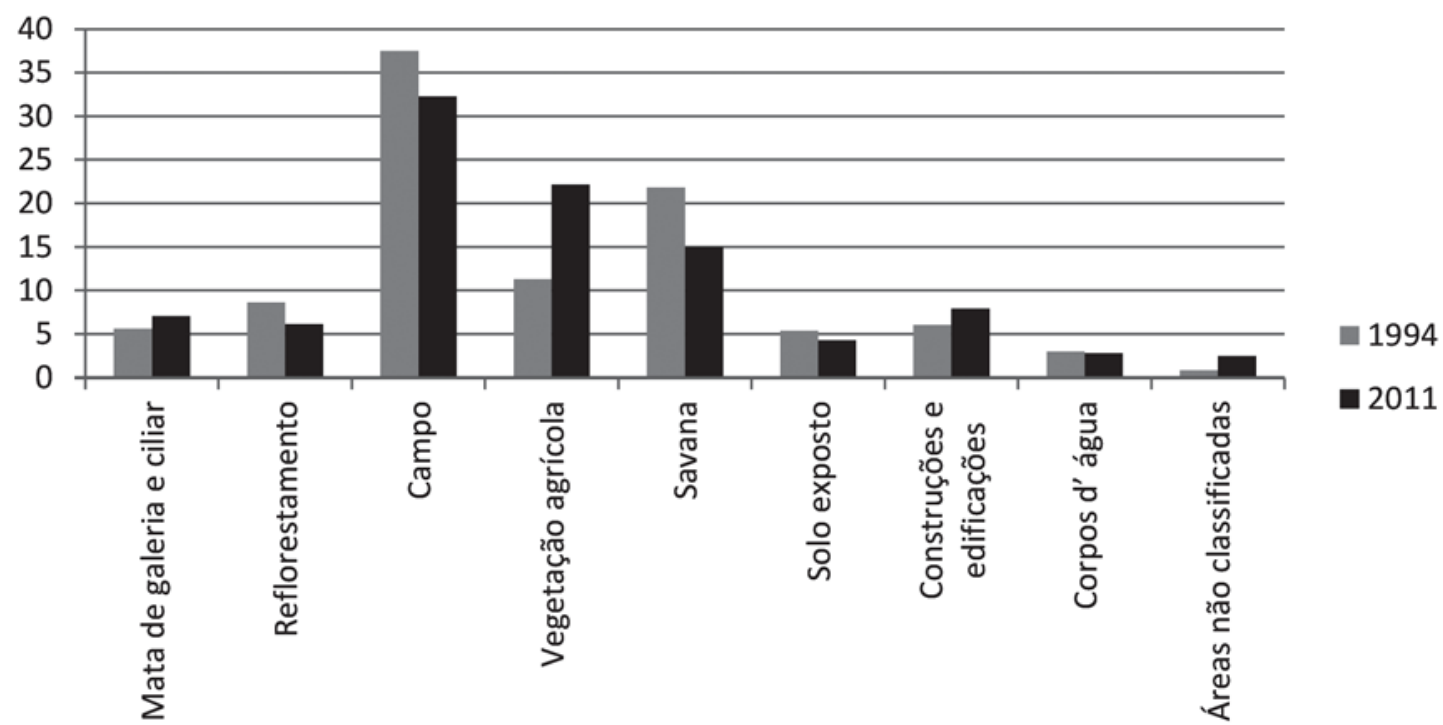

Figura 5 - Gráfico comparativo entre as áreas em porcentagem em relação à área da bacia (eixo y) e às classes (eixo x) nos anos 1994 e 2011.

Figure 5 - Comparative graph among the areas in percentage in relation to the basin area (y axis) and to the classes (x axis) for the years 1994 and 2011.

do solo terem sido englobadas nessa feição por estarem com o solo descoberto no período da obtenção da imagem, evidenciando a necessidade de uma análise temporal das feições que apresentam essa sazonalidade para uma classificação mais precisa.

O aumento na porcentagem da classe Mata de Galeria e Ciliar (aproximadamente 1,5\%) ocorreu provavelmente devido às próprias características da imagem, sendo perceptível nos mapas gerados (Figuras 3 e 4) que a classificação de 2011 obteve maior êxito na classificação dessas matas, principalmente nos locais onde essa vegetação estava mais estreita.

\section{DISCUSSÃO}

Durante o processo de classificação das imagens, foram testados diferentes parâmetros para as variáveis disponibilizadas, a fim de encontrar o valor mais adequado. O módulo ENVI FX não possui diferentes níveis de segmentação e apresenta somente um algoritmo, sendo fator limitante às diferentes segmentações necessárias devido à variedade e características dos alvos encontrados na imagem trabalhada.

A separação de determinadas feições são dificultadas em razão da sazonalidade da vegetação natural e das confusões espectrais presentes entre as classes temáticas distintas (SANO et al., 2007). Tendo em vista que as imagens apresentam características próprias relacionadas à época do ano em que a imagem foi captada pelo sensor, a segmentação de vegetação e não vegetação baseada no NDVI deve levar em consideração a assinatura espectral dos alvos e o seu comportamento em relação à sazonalidade climática da região. Além disso, a metodologia adotada utiliza atributos dos segmentos gerados para a formulação das regras de classificação, estando diretamente ligados à qualidade da segmentação e à homogeneidade dos alvos em relação a algum atributo que permita sua extração. Dessa forma, algumas medidas podem ser tomadas, a fim de reduzir os problemas de confusão entre as classes temáticas observados no processo de classificação e exemplificados nos resultados. Entre essas medidas, encontra-se a utilização de imagens com melhores resoluções espaciais, espectrais e radiométricas, assim como a utilização de mais dados auxiliares (AMARAL et al., 2009).

A análise temporal da região como ação remediadora das confusões relacionadas à classificação de vegetações sazonais, como o Cerrado, pode auxiliar no melhor desempenho da classificação proposta. Esse é o enfoque 
de estudos que têm sido realizados com o intuito de separar as fitofisionomias do Cerrado (FERREIRA et al., 2005; LIESENBERG et al., 2007). A utilização de shapefiles de estradas e limites urbanos como dados auxiliares também pode contribuir para melhorar a extração dos segmentos da classe construções e edificações, que é bastante heterogênea, naturalmente.

Ao analisar a matriz de confusão gerada (Tabela 1) para o cálculo do índice Kappa, foi possível constatar que a menor exatidão temática apresentada foi entre as classes temáticas campo e savana. As análises dos registros de campo levantaram a hipótese de que isso ocorreu, provavelmente, devido à fitofisionomia de Cerrado ralo que está englobado dentro da classe Savana. Essa fitofisionomia apresenta um estrato arbóreo pouco robusto, podendo ter uma resposta espectral semelhante à das fitofisionomias de campo. Outra hipótese que pode ter influenciado na exatidão temática observada é devida à resolução espacial da imagem. As imagens Landsat utilizadas na classificação apresentam um pixel de $30 \mathrm{~m}$, e essa resolução espacial não representa, de forma eficaz, as análises pontuais de GPS coletadas em campo, resultando em diminuição do índice de exatidão temática.

Os mapas gerados através da classificação possuem importantes informações visuais a respeito da dinâmica de expansão ou retração das classes temáticas ao longo dos anos, sendo possível perceber o avanço das práticas agrícolas entre os anos 1994 e 2011 . Entre todas as modificações de uso e ocupação do solo que ocorreram entre os anos 1994 e 2011, a vegetação agrícola foi a mais expressiva, com aumento de aproximadamente $11 \%$ da área da bacia; assim como forte queda da vegetação natural, como a classe savana, que teve redução de aproximadamente $6 \%$. Dessa forma, a bacia apresenta uso predominantemente agrícola. De acordo com Ferreira (1992), esse tipo de bacia pode apresentar alto valor de carga de fósforo e nitrogênio por unidade de área, em comparação com áreas de vegetação natural, conforme constatado nas sub-bacias Olária e Capão Comprido da Bacia do Alto do Descoberto. Esse alto valor de nitrogênio e fósforo pode afetar a qualidade da água devido a processos como a eutrofização. Além disso, estudos de sedimentologia realizados na área estudada revelaram que o uso agrícola do solo pode ocasionar maior perda do solo em relação às regiões tipicamente urbanas, caso não haja manejo adequado e desenvolvimento de práticas conservacionistas
(BICALHO, 2006). Portanto, o uso e ocupação do solo impactam ambientalmente as bacias hidrográficas, gerando diminuição da cobertura vegetal, erosão, poluição dos solos e da água, assim como alteração do microclima da região(SCHIVAETTI; CAMARGO, 2002; LIMA, 2004). Dessa forma, práticas de manejo e de conservação associadas às práticas agrícolas, assim como políticas de contenção da expansão descontrolada, devem ser aplicadas em áreas de sensibilidade ambiental, como é o caso da Bacia do Alto do Descoberto, área de influência de importante reservatório de água para consumo humano.

As análises realizadas neste estudo evidenciaram as conversões de áreas naturais para áreas de uso antrópico entre os anos 1994 e 2011 e os possíveis impactos na qualidade da água do reservatório associados a tal uso. A constatação dessa dinâmica de uso e ocupação do solo na bacia ressalta a importância de planejamento adequado nessa região para que não haja comprometimento desse manancial.

\section{CONCLUSÃO}

Os mapas gerados a partir de classificações baseadas em regras e lógica nebulosa apresentaram desempenho muito bom, com o índice de exatidão temática (Kappa) de 64\%. Esses mapas são importantes para a espacialização das classes temáticas e para obter uma análise visual da evolução dessas classes ao longo dos anos.

O workflow ENVI FX possui algumas limitações que dificultam a classificação da imagem como um todo, e entre essas limitações está a segmentação não individualizada por feição e em não possuir outros tipos de algoritmos para segmentação. Outra limitação presente na análise foram as características da imagem utilizada e a heterogeneidade dos segmentos das classes. Apesar disso, a metodologia adotada mostrou-se satisfatória na classificação das classes temáticas propostas.

A acurácia do classificador pode ser melhorada por meio da utilização de outros dados auxiliares, como shapefiles de estradas e limites urbanos, entre outros, assim como por meio da utilização de imagens com altas resoluções espaciais, temporais e espectrais.

Por meio das análises das modificações na extensão das classes temáticas na região da bacia, foi possível perceber nítida expansão agrícola e diminuição das

Revista Árvore, Viçosa-MG, v.39, n.1, p.25-36, 2015

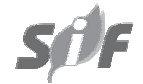


áreas naturais, como campo e savana. Nesse sentido, os resultados corroboram a hipótese de que essa bacia sofre pressões ambientais, o que pode impactar seriamente os recursos hídricos da bacia, que abastece grande parte do Distrito Federal.

Dessa forma, mais estudos são necessários para melhor definir os padrões desse uso e ocupação, com o intuito de subsidiar a tomada de decisões em relação à contenção dessa expansão observada e ao desenvolvimento sustentável da Bacia do Alto do Descoberto.

\section{AGRADECIMENTOS}

À FINEP, ao CNPq e à FAP-DF, pelo financiamento do Projeto REMISA (rede 16), por intermédio da Rede Centro-Oeste; ao CNPq, pela disponibilização de uma bolsa técnica (DTI-C); ao responsável pelo Laboratório de Sensoriamento Remoto e Análise Espacial (LSRAE) do IG/UnB, pela disponibilização da infraestrutura e do software ENVI EX; a ESRI, pela disponibilização do Pacote de ferramentas que compõem a Família ArcGis 10, por intermédio do contrato $\mathrm{N}^{\circ} 2011$ MLK 8733; e à IMAGEM, pelo apoio e viabilidade da concretização do termo de uso entre o IG e a ESRI e pelo suporte aos softwares.

\section{REFERÊNCIAS}

AMARAL, M. V. F; DE SOUZA, A. L.; SOARES, V. P.; SOARES, C. P. B.; LEITE, H. G.; MARTINS, S. V.; FERNANDES FILHO, E. I.; DE LANA, J. M. Avaliação e comparação de métodos de classificação de imagens de satélites para o mapeamento de estádios de sucessão florestal. Revista Árvore, v.33, n.3, p.369-378, 2009.

ARCOVA, F. C. S.; CICCO, V. Qualidade da água de microbacias com diferentes usos do solo na região de Cunha, Estado de São Paulo. Scientia Forestalis, v.5, n.6, p.125-134, 1999.

BICALHO, C. C. Estudo do transporte de sedimentos em suspensão na Bacia do Rio Descoberto. 2006. 123f. Dissertação (Mestrado em Tecnologia Ambiental e Recursos Hídricos) - Universidade de Brasília, Brasília, 2006.

BRASIL. SEAPA; ADASA; CAESB; EMATER-DF; IBRAM; MMA e ICMBIO. Adequação ambiental da reserva ecológica e das propriedades rurais às margens do Lago Descoberto. Brasília: 2009.
CARVALHO, N.O.; FILIZOLA JÚNIOR, N.P.; SANTOS, P.M.C.; LIMA, J.E.F.W. Guia de práticas sedimentométricas. Brasília: ANEEL, 2000. 154p.

CASTEJON, E.; DE PINHO, C. M. D. TA NDVI Segmenter. 2011. [S.L.]: InterIMAGE wiki Disponível em: $<$ http://wiki.dpi.inpe.br/ doku.php?id=interimage:operators documentation>. Acesso em: $10 \mathrm{de}$ fev. de 2013.

COHEN, J. A coefficient of agreement for nominal scales. Educational and Psychological Measurement, v.20, n.1, p.37-46, 1960.

DEFINIENS E-Cognition. Definiens Understanding images software. [S.L.]: Trimble. 2012. Disponível em: <http://www.ecognition.com>. Acesso em 20 de jan. de 2013.

DONATIO, N. M. M.; GALBIATTI, J. A.; DE PAULA, R. C. Qualidade da água de nascentes com diferentes usos do solo na bacia hidrográfica do córrego Rico, São Paulo, Brasil. Engenharia Agrícola, v.25, n.1, p.115-125, 2005.

GREEN ENGENHARIA AMBIENTAL LTDA. Plano de gestão da APA Federal da Bacia do rio Descoberto, DF/GO (documento preliminar). 1998. Brasília/DF: ANA. Disponível em: <http:// www.ana.gov.br/AcoesAdministrativas/CDOC/ docs/planos_diretores/Descoberto/ pdfs/ DOC_PRELIMINAR.pdf $>$ Acesso: 28 de jan. de 2013.

ENVI. ENVI Feature Extraction Module: User's guide. [S.L.]: ITT visual information solution, 2008.

FERREIRA, M.E.; PECCININI, A.A; FERREIRA, L.G.; HUETE, A.R. Análise da sazonalidade de paisagens antrópicas e nativas do bioma cerrado através dos produtos MODIS, índices de vegetação, área foliar e atividade fotossintética. In: SIMPÓSIO BRASILEIRO DE

SENSORIAMENTO REMOTO, 12., 2005, Goiânia. Anais... Goiânia: 2005. p.505-512.

FERREIRA, V. A. P.; BORGES, M. N.; ANJOS, E. F. S. Determinação dos aportes totais e carga por

Revista Árvore, Viçosa-MG, v.39, n.1, p.25-36, 2015 
unidade de área de nitrogênio e fósforo com base na caracterização do uso e ocupação do solo nas Bacias dos Lagos Descoberto e Santa MariaBrasília-DF. Acta Limnologica

Brasiliensia, v.4, n.1, p.163-174, 1992.

FONSECA, L. M. G. Processamento digital de imagens. São José dos Campos: Instituto Nacional de Pesquisas Espaciais (INPE), 2000. 105p.

HAY, G. J.; CASTILLA, G. Object-based image analysis: strengths, weaknesses, opportunities and threats (swot). In: BRIDGING REMOTE SENSING AND GIS: INTERNATIONAL SYMPOSIUM ON OBJECT-BASED IMAGE ANALYSIS, 2006, SALZBURG. The International Archives of the Photogrammetry, Remote Sensing and Spatial Information Science. Com VI, WG VI/4, 2006. p.1-5.

INTERIMAGE. Interimage: Interpreting image freely. 2010. [S.L.]: interimage. Disponível em: <http://www.lvc.ele.puc-rio.br/projects/interimage/ $>$. Acesso em: 08 de jan. de 2013.

LIESENBERG, V.; PONZONI, F. J.; GALVÃO, L. S. Análise da dinâmica sazonal e separabilidade espectral de algumas fitofisionomias do cerrado com índices de vegetação dos sensores MODIS/ TERRA e AQUA. Revista Árvore, v.31, n.2, p.295-305, 2007.

LIMA, J. B. M. Estudo de redes de monitoramento de qualidade de água superficiais - o caso da Bacia do Rio Descoberto. 2004. 112f. Dissertação (Mestrado em Tecnologia Ambiental e Recursos Hídrico) Universidade de Brasília, Brasília, 2004.

LOCK, R. E. M.; KIRCHNER, F. F. Classificação de imagens multiespectrais de landsat TM e feições de textura: mapeamento da cobertura da terra. Floresta, v.27, n.12, p.41-58, 1997.

MACEDO, M. J. B. A influência do uso, da ocupação e da conservação do solo na qualidade da água de abastecimento: o caso da bacia hidrográfica do lago do Descoberto. 2004. 172f. Dissertação (Mestrado em Planejamento e Gestão Ambiental) Universidade Católica de Brasília, Brasília, 2004.

RIBEIRO, J. F.; WALTER, B. M. T. Fitofisionomias do bioma Cerrado. In: SANO, S. M.; ALMEIDA, S. P. (Ed.). Cerrado: ambiente e flora. Brasília, DF: Embrapa Cerrados, 1998. p.87-166.

ROUSE,J.W.; HAAS, R.H.; SCHELL, J.A.; DEERING, D.W. Monitoring vegetation systems in the great plains with ERTS. In: EARTH RESOURCES TECHNOLOGY SATTELITE-1 SYMPOSIUM, 1973, Washington. Proceedings. Washington: 1973. p.309-317.

SANO, E.E.; FERREIRA, L.G.; ASNER, G.P.; STEINKE, E.T. Spatial and temporal probabilities of obtaining cloud-free Landsat images over the Brazilian tropical savanna. International Journal of Remote Sensing, v.28, n.12, p.2739-2752, 2007.

SANO, E.E.; ROSA, R.; BRITO, J.L.S.; FERREIRA, L.G; BEZERRA, H.S. Mapeamento da cobertura vegetal natural e antrópica do bioma Cerrado por meio de imagens Landsat ETM+. In: SIMPÓSIO BRASILEIRO DE SENSORIAMENTO REMOTO, 14., 2009, Natal. Anais... Natal: INPE, 2009. p.1199-1206.

SCHIAVETTI, A.; CAMARGO, A.F.M. Conceitos de bacias hidrográficas: teorias e aplicações. Ilhéus: Editus, 2002. 289p.

SPERA, S. T.; REATTO, A.; MARTINS, E.S.; CARDOSO, E. A.; CARVALHO Jr., O. A.; GUIMARÃES, R.; FARIAS, M. F. R.; SILVA, A. V. Aptidão agrícola das Terras da bacia do Alto curso do Rio Descoberto. DF/ GO escala de 1:100.000. Planaltina, DF: Embrapa Cerrados, 2003.

ZADEH, L. A. Fuzzy logic and approximate reasoning. Synthese, v.30, n.3, p.407-428, 1975. 